\title{
Estudo comparativo entre técnicas para fixação de placa metálica em esclera de coelhos
}

\author{
Scleral metal plate fixation. An experimental study
}

\author{
Sandra Lucia Dias Ramos de Abreu ${ }^{1}$ \\ Harley E. A. Bicas ${ }^{2}$
}

\section{RESUMO}

Objetivo: Comparação entre dois diferentes métodos para fixação escleral de placa metálica em coelhos, utilizando-se adesivo de cianoacrilato e fio de sutura Mersilene ${ }^{\odot}$ 6.0. Métodos: Vinte e sete coelhos adultos foram operados sob anestesia geral e seus olhos foram examinados quanto à reação inflamatória ocular no $8^{\circ}, 23^{\circ}$ e $38^{\circ}$ dia de pós-operatórios. Foi estudada a aderência da placa à esclera por meio das forças de tração tangencial e perpendicular. Resultados: Sinais clínicos de reação inflamatória estiveram presentes até o $23^{\circ}$ dia em todos os olhos e foram levemente mais intensos nos olhos que usaram cianoacrilato. Exame microscópico mostrou reações até o $38^{\circ}$ dia em todos os olhos. Diferentes forças de tração foram aplicadas nas placas e variavam de 20 a 80 gf. Forças de tração de 80 gf não produziram descolamento em todas as placas até o $38^{\circ}$ dia. Conclusões: A fixação da placa metálica na esclera em coelhos pode ser obtida com a utilização do fio de sutura ou do adesivo de cianoacrilato.

Descritores: Cianoacrilatos; Suturas; Resistência à tração; Coelhos

\section{INTRODUÇÃOO}

Estudos experimentais demonstram a possibilidade de estabilização do olho, sem impedir rotações, por meio de campos magnéticos. Essa linha de pesquisa, com estimulantes perspectivas de aplicação (neutralização de nistagmos, obtenção de uma posição ocular normal após uma correção de estrabismo e, principalmente, sua estabilização ao longo do tempo) requer que as forças de contenção se dêem por um circuito magnético em que o elemento gerador do campo (um ímã permanente) se situe na região periocular (fixado à órbita) e que o elemento complementar seja uma placa ferromagnética, presa ao olho ${ }^{(1,2)}$.

Este trabalho experimental estuda as possibilidades técnicas de fixação da placa ferromagnética na esclera de coelhos, pois não existe nenhum relato comparativo entre o efeito do adesivo tecidual (cianoacrilato) e do fio de sutura inabsorvível (Mersilene ${ }^{\odot} 6.0$ ), na implantação escleral da placa.

Os objetivos do presente estudo foram:

1) Avaliação clínica da reação ocular inflamatória ao adesivo tecidual cianoacrilato e ao material de sutura inabsorvível após a fixação da placa metálica à esclera.

2) Estudo histopatológico das fases inflamatórias aguda e crônica do olho na implantação da placa, utilizando o adesivo cianoacrilato e o fio de sutura inabsorvível.

3) Medidas das forças de tração tangencial e perpendicular aplicadas sobre a placa metálica e avaliação da sua adesão à esclera, comparando o adesivo cianoacrilato e o fio de sutura inabsorvível. 


\section{MÉTODOS}

Para a realização deste trabalho experimental, longitudinal e duplo mascarado, 27 coelhos machos albinos, da raça Nova Zelândia, com peso variando entre 2,5 e 3,0 kg, sem sinais de doença, foram divididos em três grupos. Em todos os experimentos, ambos os olhos de cada coelho foram operados:

a) Grupo A com 12 coelhos ( 24 olhos), para estudo clínico e histopatológico da reação inflamatória da placa metálica fixada na esclera.

b) Grupo B com 3 coelhos (6 olhos), para controle clínico e histopatológico de cicatrização da conjuntiva.

c) Grupo C com 12 coelhos (24 olhos), para medida das forças tangencial e perpendicular aplicadas na placa metálica.

Para a realização dos procedimentos cirúrgicos, avaliação clínica da reação inflamatória e medidas das forças de tração tangencial e perpendicular aplicadas na placa, cada animal foi submetido à anestesia geral, sob a supervisão de veterinário. Foi utilizada injeção intramuscular de cloridrato de ketamina, em dose de $12 \mathrm{mg} / \mathrm{kg}$ peso, associada ao cloridrato de xilazina a $2 \%$, em dose de $4 \mathrm{mg} / \mathrm{kg}$ peso. Todos os animais dos grupos A, B e C foram sacrificados, após períodos pós-operatórios fixados ( $8^{\circ}, 23^{\circ}$ e $38^{\circ}$ dias) com injeção endovenosa de $1 \mathrm{ml} \mathrm{de}$ tiopental associada a $2,5 \mathrm{ml}$ de cloreto de potássio sob a supervisão de veterinário.

Foram estudados 4 coelhos (8 olhos) do grupo A, 1 coelho ( 2 olhos) do grupo B e 4 coelhos ( 8 olhos) do grupo C, totalizando 9 coelhos (18 olhos), em cada período pós-operatório ( $8^{\circ}$, $23^{\circ}$ e $38^{\circ}$ dias).

Em cada coelho dos grupos A e C, a fixação da placa metálica na esclera em um dos olhos foi realizada com adesivo tecidual (cianoacrilato), sendo denominados subgrupos A1 e $\mathrm{C} 1$, e, no olho contralateral, foi utilizada a sutura com fio inabsorvível, sendo denominados subgrupos A2 e C2. Os olhos operados dos grupos A e C foram distribuídos a partir de sorteio, para o uso do adesivo tecidual cianoacrilato ou do material de sutura inabsorvível.

Todas as placas utilizadas possuíam $0,5 \mathrm{~mm}$ de espessura, superfície metálica polida medindo $6 \times 10 \mathrm{~mm}$ e raio de curvatura em torno de $12,5 \mathrm{~mm}$. Todas as arestas foram arredondadas. Pequenos orifícios $(0,8 \mathrm{~mm}$ de diâmetro) existiam em cada extremidade, através dos quais as suturas foram passadas e fixadas à esclera.

Reação de corpo estranho acompanha toda sutura cirúrgica e sua intensidade varia com o material do fio utilizado. Fios inabsorvíveis ocasionam menos reação do que os absorvíveis, razão da escolha do fio Mersilene ${ }^{\odot} 6.0$.

Pela sua capacidade adesiva verificada em trabalhos ${ }^{(3-7)}$ optou-se pela utilização do éster de cianoacrilato (Super Bonder, Loctite) para o experimento.

\section{Procedimento cirúrgico}

Em todos os olhos do grupo A (24 olhos) e do grupo C (24 olhos), realizou-se incisão e abertura da conjuntiva no lado temporal (entre 7 e 11 horas no olho direito, 1 e 5 horas no olho esquerdo), com liberação das aderências e preensão do músculo reto lateral com o gancho de estrabismo (Figura 1). O músculo reto lateral foi apenas afastado, permanecendo a esclera subjacente exposta para a colocação da placa metálica. A fixação do menor lado da placa $(6 \mathrm{~mm})$ foi realizada paralela ao limbo e a uma distância de $3 \mathrm{~mm}$ dele (Figura 2). Após a fixação da placa na esclera, o músculo reto lateral foi liberado e a colocação da conjuntiva foi realizada no local primitivo, sem sutura. Não foram utilizados colírios, curativo oclusivo e colar de proteção no período pós-operatório imediato. No grupo C, além da fixação da placa, colocou-se pelos orifícios de sua face anterior e sem fixá-la na esclera, uma alça de fio de Poliamida $0,2 \mathrm{~mm}$, para auxílio na tração. Nos olhos do grupo controle B (6 olhos), foi realizada incisão da conjuntiva ( 7 a 11 horas no olho direito, 1 a 5 horas no olho esquerdo) e, após a liberação das aderências e preensão do músculo reto lateral, a esclera exposta foi submetida à irrigação com $5 \mathrm{ml}$ de solução fisiológica a $0,9 \%$. A reposição da conjuntiva na sua posição primitiva foi realizada sem sutura.

\section{Exame clínico}

Dois observadores independentes, que desconheciam a técnica cirúrgica utilizada, observaram a evolução dos sinais clínicos da inflamação dos olhos nos animais dos grupos A e B. Foram utilizados os seguintes parâmetros para as avaliações: hiperemia conjuntival - ausente (a), presente mas discreta (+), moderada (++) ou acentuada (+++); secreção conjuntival - ausente (a) ou presente (p); presença de muco - ausente (a) ou presente (p).

\section{Exame histopatológico}

Após o exame clínico, de acordo com os períodos pósoperatórios de $8^{\circ}, 23^{\circ}$ e $38^{\circ}$ dias, nos animais dos grupos A e B, sob anestesia geral, foram realizadas as retiradas dos globos oculares por meio da enucleação (mas preservando-se a placa

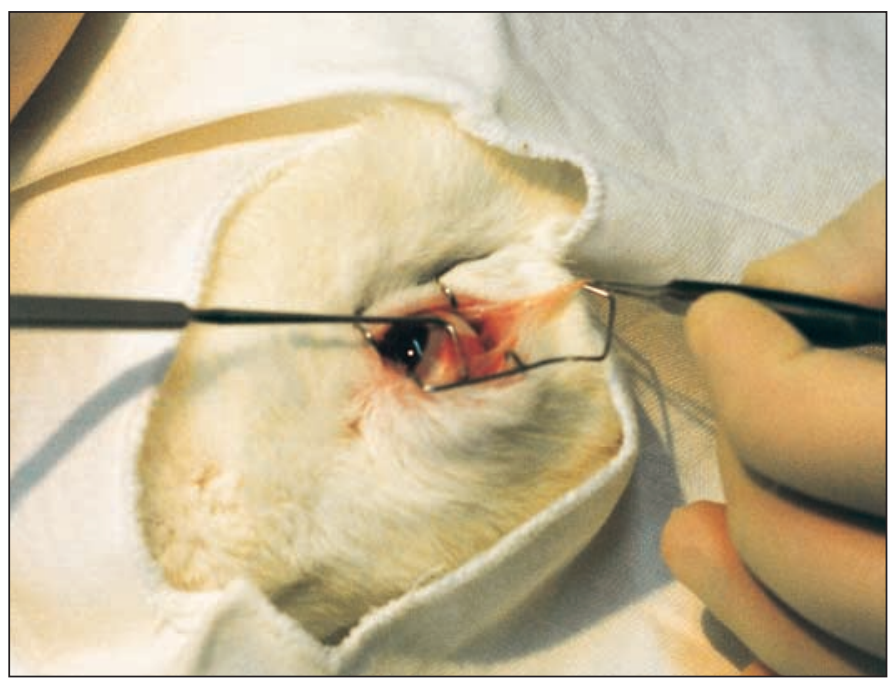

Figura 1 - Abertura da conjuntiva e preensão do músculo reto lateral 


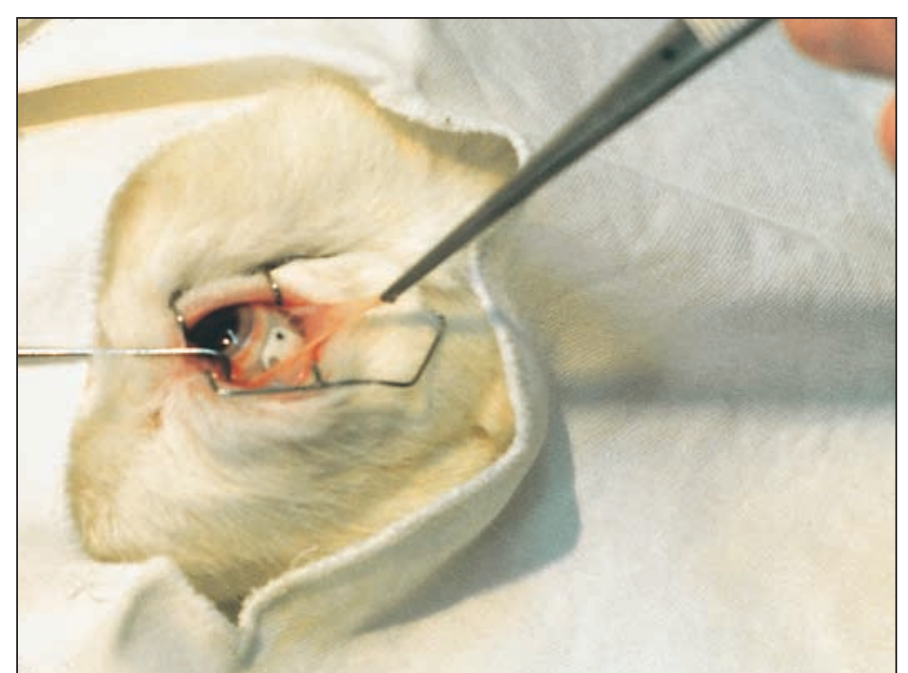

Figura 2 - Fixação do menor lado da placa $(6 \mathrm{~mm})$ paralelo ao limbo a uma distância de $3 \mathrm{~mm}$

e a conjuntiva no local a ser examinado). Os globos oculares foram colocados em frascos numerados com a solução fixadora de Bouin durante 24 horas, sendo depois transferidos, no laboratório, para a solução fixadora de formol tamponado, na qual permaneceram até o momento da clivagem. Lâminas com cortes de 4 micra foram montadas, preparadas e coradas com hematoxilina eosina e tricrômico de Gomory. As análises microscópicas foram realizadas, individualmente, por duas patologistas que desconheciam a técnica cirúrgica utilizada em cada olho e os períodos pós-operatórios. Foi utilizado microscópio óptico da marca Olympus, com objetivas de 10 e 40 vezes de aumento, oculares de 10 vezes, correspondendo a aumentos de 100 e 400 vezes, respectivamente.

\section{Medidas de tração}

Foram realizadas com o dinamômetro de Wagner, com a escala dividida em intervalos de 1 gf (grama-força) até o máximo de $115 \mathrm{gf}$. Para a medida, o gancho do aparelho foi colocado na alça do fio de Poliamida existente na placa metálica e dois tipos de tração foram aplicadas em seqüência: forças progressivas de tração tangencial com 20, 40, 60 e 80 gf.

\section{Métodos estatísticos}

Foram realizadas análises descritivas quando nenhum teste estatístico de significância era adequado ou se a simples observação clínica tornava-se suficiente para a tomada de decisões. Para outras variáveis foi utilizado o teste do Quiquadrado. Adotou-se o nível de significância de 5\%.

\section{RESULTADOS}

\section{A) Observações clínicas}

Os aspectos clínicos da reação inflamatória nos olhos dos coelhos do grupo A estão representados na Tabela 1 .

\begin{tabular}{|c|c|c|c|c|c|c|c|}
\hline \multirow[t]{2}{*}{ PO } & \multirow[t]{2}{*}{ Animal } & \multicolumn{2}{|c|}{ Hiperemia } & \multicolumn{2}{|c|}{ Secreção } & \multicolumn{2}{|c|}{ Muco } \\
\hline & & $\overline{A 1}$ & A2 & A1 & $\overline{A 2}$ & $\overline{A 1}$ & A2 \\
\hline \multirow[t]{4}{*}{$8^{\circ}$} & 02 & ++ & + & a & $a$ & $p$ & a \\
\hline & 04 & +++ & + & $\mathrm{a}$ & $a$ & $p$ & $\mathrm{a}$ \\
\hline & 05 & +++ & + & a & a & $p$ & $a$ \\
\hline & 06 & ++ & + & $a$ & a & $p$ & $a$ \\
\hline \multirow[t]{4}{*}{$23^{\circ}$} & 03 & + & $a$ & $a$ & a & $p$ & a \\
\hline & 07 & + & $a$ & $\mathrm{a}$ & a & $a$ & $a$ \\
\hline & 14 & + & + & $p$ & $p$ & $p$ & a \\
\hline & 15 & + & + & $a$ & a & $a$ & $a$ \\
\hline \multirow[t]{4}{*}{$38^{\circ}$} & 09 & a & $a$ & $a$ & a & $a$ & $a$ \\
\hline & 10 & a & a & a & a & $\mathrm{a}$ & $a$ \\
\hline & 11 & a & a & $\mathrm{a}$ & a & $a$ & $a$ \\
\hline & 12 & a & a & $a$ & a & a & a \\
\hline
\end{tabular}

No grupo controle B, no 8o dia pós-operatório, sinais de hiperemia e secreção conjuntival não foram observados. No $23^{\circ}$ dia de pós-operatório, foram descritos hiperemia e presença de secreção conjuntival em um olho. Ausência de sinais inflamatórios no $38^{\circ}$ dia pós-operatório.

\section{B) Histopatologia}

O número de olhos com sinais histológicos encontrados nas fases inflamatórias aguda e crônica, após os procedimentos cirúrgicos, em diferentes períodos pós-operatórios (PO), são descritos na Tabela 2.

\section{C) Medidas de tração}

Pelas medidas das forças de tração tangencial e perpendicular com o dinamômetro de Wagner no 8 dia pós-operatório, uma placa do subgrupo $\mathrm{C} 1$ (cianoacrilato) e uma do subgrupo C2 (sutura) foram descoladas com a aplicação da força tangencial de 60 gf. Ainda no subgrupo C2 (sutura), uma placa foi descolada com a força perpendicular de 80 gf. No $23^{\circ}$ dia pósoperatório, foram descoladas uma placa do subgrupo $\mathrm{C} 1$ e uma do subgrupo C2, devido à aplicação da força tangencial de 80 gf. As adesões entre a placa e a esclera foram conservadas em todos os oito olhos estudados no $38^{\circ}$ dia de pós-operatório, com a aplicação da força de 80 gf nos movimentos tangencial e perpendicular.

\section{DISCUSSÃO}

\section{A) Exame clínico - 8 dia pós-operatório}

Ocorreu um quadro de normalidade no grupo controle B.

Houve diferença significativa em relação à intensidade da hiperemia conjuntival entre os subgrupos A1 e A2, de acordo 


\begin{tabular}{|c|c|c|c|c|c|c|c|c|c|c|c|}
\hline \multirow[b]{2}{*}{ Fases } & \multirow[b]{2}{*}{ Sinais } & \multirow{2}{*}{$\begin{array}{c}\text { Grupo } \\
\text { PO }\end{array}$} & \multicolumn{3}{|c|}{ A1 Adesivo } & \multicolumn{3}{|c|}{ A2 Sutura } & \multicolumn{3}{|c|}{ B Controle } \\
\hline & & & 8 & 23 & 38 & 8 & 23 & 38 & 8 & 23 & 38 \\
\hline \multirow[t]{3}{*}{ Aguda } & Congestão vascular & & 4 & 4 & 1 & 2 & 2 & 2 & 0 & 0 & 0 \\
\hline & Infiltrado neutrofílico & & 0 & 3 & 1 & 3 & 0 & 0 & 0 & 0 & 0 \\
\hline & Infiltrado linfocitário & & 4 & 4 & 4 & 3 & 4 & 3 & 0 & 0 & 2 \\
\hline \multirow{2}{*}{ Crônica } & Infiltrado Granulomatoso & & 0 & 2 & 2 & 1 & 2 & 1 & 0 & 0 & 0 \\
\hline & Fibrose & & 3 & 2 & 3 & 1 & 2 & 1 & 0 & 1 & 0 \\
\hline
\end{tabular}

com o teste do qui-quadrado, utilizado para análise estatística $(\mathrm{p}=0,0183)$. No subgrupo A1, ocorreu uma reação inflamatória aguda ao efeito irritativo do cianoacrilato nos quatro olhos, que pode surgir após sua polimerização com a produção de formaldeído e alquil ${ }^{(3-4)}$. No subgrupo A2, a presença do material de sutura ocasionou uma hiperemia leve nos quatro olhos. Ausência de secreção conjuntival nos olhos dos subgrupos A1 e A2.

Ocorreu diferença significativa em relação à presença de secreção mucosa na região da placa entre os subgrupos A1 e A2 ( $\mathrm{p}=0,0047)$. Pela reação da cola em contato com a placa, todos os quatro olhos do subgrupo A1 apresentaram secreção mucosa.

\section{B) Exame clínico - 23 dia pós-operatório}

No grupo controle B foi detectada conjuntivite bacteriana com hiperemia conjuntival leve e secreção de conjuntiva em um olho (animal 08). Outros olhos sem alterações.

Não houve diferença significativa em relação à intensidade da hiperemia conjuntival $(\mathrm{p}=0,1025)$ e em relação à freqüência da secreção mucosa $(\mathrm{p}=0,1025)$ entre os olhos dos subgrupos A1 e A2. Apesar desse resultado, surgiu a presença de muco nos olhos dos animais 03 e 14 (subgrupo A1). Secreção de conjuntiva nos dois olhos do animal 14, foi atribuída à conjuntivite bacteriana bilateral.

\section{C) Exame clínico - 38 dia pós-operatório}

O grupo controle B apresentou um quadro sem alterações clínicas.

Ausência de hiperemia conjuntival, secreção de conjuntiva e secreção mucosa na placa metálica em todos os olhos dos subgrupos A1 e A2 (ou seja, todos eles apresentaram normalidade clínica).

\section{D) Exame histopatológico - 8o dia pós-operatório}

Não foram observadas respostas inflamatórias aguda e crônica no grupo controle B.

O estudo estatístico realizado não revelou diferença significativa em relação ao número de olhos com sinais histopatológicos na fase inflamatória aguda entre os subgrupos A1 e A2, com nível de significância discretamente superior a 5\% $(\mathrm{p}=0,0578)$. Em relação à fase inflamatória crônica, não ocorreu diferença significativa entre os subgrupos A1 e A2 ( $p=0,3943)$, de acordo com o teste do qui-quadrado, em relação ao número de olhos com sinais histopatológicos. Ocorreu um aumento no número de células de infiltrado linfocitário, de leve a moderado, no subgrupo A1, em relação ao subgrupo A2, provavelmente como reação cicatricial ao adesivo. Surgiram células gigantes tipo Langhans no subgrupo A2, como reação de corpo estranho ao fio de sutura. Observou-se uma fibrose mais duradoura no subgrupo A1 em relação ao subgrupo A2, pelo acúmulo continuado de colágeno (fibroblastos).

\section{E) Exame histopatológico - 23 dia pós-operatório}

O grupo controle B não apresentou sinais de reação inflamatória aguda. Apenas um olho, comprometido com conjuntivite bacteriana apresentou fibrose na fase inflamatória crônica.

Não houve diferença significativa em relação ao número de olhos com sinais histopatológicos, entre os subgrupos A1 e A2 ( $p=0,2568$ ), de acordo com o teste do qui-quadrado, utilizado para a análise estatística. Presença de maior número de células no infiltrado neutrofílico de moderado a acentuado permaneceu no subgrupo A1, como resposta ao adesivo. Não houve diferença significativa em relação à fase inflamatória crônica entre os subgrupos A1 e A2 ( $\mathrm{p}=0,6357)$, em relação ao número de olhos com sinais histopatológicos, de acordo com teste do qui-quadrado.

\section{F) Exame histopatológico - 38 dia pós-operatório}

O grupo controle B apresentou leve infiltrado linfocitário (dois olhos) na fase crônica, o qual está relacionado com o processo de cicatrização da conjuntiva.

Não houve diferença significativa nas fases inflamatórias aguda $(\mathrm{p}=0,2482)$ e crônica $(\mathrm{p}=0,8340)$ entre os subgrupos A1 e A2, de acordo com o teste do qui-quadrado, em relação ao número de olhos com sinais histopatológicos. Ocorreu aumento na quantidade de células no infiltrado linfocitário, granuloma de corpo estranho e fibrose no subgrupo A1, em relação ao subgrupo A2, provavelmente como reação cicatricial ao adesivo. Presença de eosinófilos no subgrupo A2 em um olho demonstrou reação de hipersensibilidade ao material de sutura.

Sinais de reação inflamatória crônica foram evidenciados no $8^{\circ}$ dia pós-operatório e conservados até o $38^{\circ}$ dia em todos os olhos com a placa metálica. O aparecimento de uma reação levemente mais intensa esteve presente nos olhos com o adesivo. 


\section{G) Medidas das forças de tração}

A adesão da placa na esclera pela cicatriz tecidual foi relativamente boa no $8^{\circ}$ dia pós-operatório, pois $75 \%$ dos olhos resistiram à tração tangencial de 80 gf. Resistiram cinco dos oito olhos $(62,5 \%)$ à tração perpendicular de 80 gf. Todas as placas continuaram aderidas à esclera com as trações de 40 gf, quando a reação cicatricial ainda estava em desenvolvimento.

No $23^{\circ}$ dia, descolamentos foram observados pela tração tangencial de 80 gf em dois olhos (uma para cada tipo de fixação), enquanto todas as placas permaneceram aderidas na esclera quando forças de $60 \mathrm{gf}$ foram aplicadas.

No $38^{\circ}$ dia pós-operatório, verificou-se que todas as placas resistiram à tração das forças tangencial e perpendicular de $80 \mathrm{gf}$, permanecendo fixas na esclera. Todas as placas que permaneceram no local após as aplicações das forças de 20 gf, 40 gf, 60 gf ou 80 gf, nos períodos pós-operatórios ( $8^{\circ}, 23^{\circ}$ e $38^{\circ}$ dias), mostram que a maioria delas ( $75 \%$ ) suportou a força de $80 \mathrm{gf}$ no $8^{\circ}$ dia.

\section{CONCLUSÕES}

1) Sinais clínicos de reação inflamatória foram observados quando a fixação da placa metálica na esclera foi realizada com o cianoacrilato ou sutura inabsorvível, sendo levemente mais intensa com o adesivo tecidual. Os sinais clínicos persistiram nos subgrupos A1 e A2 entre 2 a 3 semanas após a cirurgia ( $23^{\circ}$ dia de pós-operatório). No $38^{\circ}$ dia pós-operatório, não foi evidenciado nenhum sinal clínico de reação inflamatória em ambos os subgrupos A1 e A2.

2) O exame histopatológico nas fases inflamatórias aguda e crônica demonstrou ainda a presença de alguma reação inflamatória no $38^{\circ}$ dia pós-operatório, apesar de os sinais clínicos estarem dentro da normalidade. A resposta ao adesivo foi levemente mais intensa na fase inflamatória crônica com o aumento no número de células do infiltrado linfocitário.

3) A fixação da placa à esclera avaliada pelas medidas das forças de tração tangencial e perpendicular aplicadas sobre ela aumentou em função do período pós-operatório. No $8^{\circ}$ dia de fixação, $75 \%$ das placas metálicas não se descolaram da esclera com a aplicação das forças tangencial e perpendicular de 60 gf e $62,5 \%$ resistiram as forças de 80 gf. No $23^{\circ}$ dia, todas as placas não se descolaram com as forças tangencial e perpendicular de 60 gf e $75 \%$ resistiram às forças de 80 gf. No $38^{\circ}$ dia, todas as placas permaneceram coladas na esclera, com a aplicação de forças tangencial e perpendicular de 80 gf.

A força de tração de $80 \mathrm{gf}$ não produziu descolamento em $62,5 \%$ das placas metálicas em 8 dias, $75 \%$ no $23^{\circ}$ dia e em todas no $38^{\circ}$ dia, indicando melhor resultado com o aumento do período pós-operatório.

\section{ABSTRACT}

Purpose: To study two different methods of metal plate fixation: cyanoacrylate adhesive and Mersilene ${ }^{\odot} 6.0$ sutures. Methods: 27 adult rabbits were operated under general anesthesia and the eyes were later examined in order to determine the amount of inflammation. This was done on the $8^{\text {th }}, 23^{\text {rd }}$ and $38^{\text {th }}$ day. The adherence of the plate to the sclera was also studied under different perpendicular and tangential traction forces. A comparison was made with a control group. Results: Clinical signs of inflammatory reaction were found in all eyes in up to the $23^{\text {rd }}$ day and were slightly more intense in the eyes where cyanoacrylate was used. Microscopical signs of inflammation persisted up to $38^{\text {th }}$ day. Different traction forces were applied to the plates and varied from 20 to $80 \mathrm{gf}$. The latter were unable to detach the plate from the sclera in all eyes at the end of the 38 days. Conclusions: The fixation of metal plates on the scleral surface is a feasible method and can be performed using suture fixation or cyanoacrylate glue.

Keywords: Cyanoacrylates; Sutures; Tensile strength; Rabbits

\section{REFERÊNCIAS}

1. Bicas HEA. Geração de rotações oculares combinadas em casos de perdas de ação muscular. Modelos baseados em forças produzidas por campos magnéticos. Arq Bras Oftalmol 1996;56:550-8.

2. Bicas HEA. Ajustamentos posicionais oculares e estabilizações do equilíbrio oculomotor sem impedir rotações. Arq Bras Oftalmol 1998;61:294-304.

3. Calabria GA, Pruett RC, Refojo MF, Schepens CL. Sutureless scleral buckling. An experimental technique. Arch Ophthalmol 1970;83:613-8.

4. Gilbert GE, Grierson I, Mcleod D. Retinal pacthing: A new approach to the management of selected retinal breaks. Eye 1989;3:19-26.

5. Maguen E, Nesburn AB, Macy JI. Combined use of sodium hyaluronate and tissue adhesive in penetrating keratoplasty of corneal perforations. Ophthalmic Surg 1984; $15: 55-7$.

6. Portnoy SL, Insler MS, Kaufman HE. Surgical management of corneal ulceration and perforation. Surv Ophthalmol 1989;34:47-58.

7. Wendler ME, Falzoni WL, Falzoni R. Adesivos teciduais no tratamento de perfuração corneana. Estudo comparativo em cobaios. Arq Bras Oftalmol $1983 ; 46: 138-40$.

\title{
ABO ELETRÔNICO
}

\author{
Novo site
}

\section{Acesso: http://www.abonet.com.br}

